\title{
Bat guano as new and attractive chitin and chitosan source
}

\author{
Murat Kaya ${ }^{1,2^{*}}$, Osman Seyyar ${ }^{3}$, Talat Baran ${ }^{2,4}$ and Tuncay Turkes ${ }^{3}$
}

\begin{abstract}
Introduction: Chitin is a biopolymer that forms the exoskeleton of arthropods, and is found in the cell walls of fungi. It has a wide range of uses in fields such as cosmetics, pharmacy, medicine, bioengineering, agriculture, textiles and environmental engineering based upon its nontoxic, ecofriendly, biocompability and biodegradability characteristics. Commercially, chitin is obtained from processing the outer skeleton of Crustacea such as shrimp, crab, prawn and crayfish after they have been consumed as food. The study aims to examine the nature of bat guano and to determine if it is a practical source of chitin, which has not been done previously.

Results: In this study, the chitin content of dry bat guano samples was found to be $28 \%$. The bat guano, which was collected from Karacamal Cave, came from the bat species Rhinolophus hipposideros. The chitosan yield of this chitin was 79\%. The chitin produced from the bat guano was determined to be in the alpha form according to Fourier transform infrared spectroscopy (FTIR) results. The crystallinity of the chitin and chitosan samples was calculated as 85.49 and $58.51 \%$ respectively by X-ray crystallography (XRD) experiments. According to scanning electron microscope (SEM) micrographs, the chitin and chitosan structures were shaped like nanofibers. The thermogravimetric analysis (TGA) results showed that both chitin and chitosan had two step weight losses, which are characteristic of these materials. The nitrogen content of the chitin and chitosan was 6.47 and $7.3 \%$ respectively according to the elemental analysis results.
\end{abstract}

Conclusions: In this research, it has been observed that bat guano can be considered to be an alternative source of chitin and chitosan to crab, shrimp, crayfish and krill.

Keywords: Bat guano, Chitin, Chitosan, Characterization, Nanofibre

\section{Introduction}

Chitin is a structural aminopolysaccharide that and is found in the cell walls of yeast, fungi, protists and diatoms as well forms the exoskeletons of broad variety of invertebrates including sponges, worms, mollusks and, especially, arthropods species. It has a wide range of uses in fields such as cosmetics, pharmacy, medicine, bioengineering, biological materials science, agriculture, textiles and environmental engineering based upon its nontoxic, ecofriendly, biocompability and biodegradability characteristics [1-5]. Commercially, chitin is obtained from processing the outer skeleton of Crustacea such as shrimp, crab, prawn and crayfish after they have

\footnotetext{
* Correspondence: muratkaya3806@yahoo.com

'Department of Biotechnology and Molecular Biology, Faculty of Science and Letters Aksaray University, Aksaray 68100, Turkey

${ }^{2}$ Science and Technology Application and Research Center, Aksaray University, Aksaray 68100, Turkey

Full list of author information is available at the end of the article
}

been consumed as food [6,7]. Recently, there has been a need for new chitin sources in line with the discovery of new usage areas for chitin and its derivatives in areas such as biotechnology and extreme biomimetics [8-10]. Some studies have considered the utilization of fungi, insects and corals as alternative chitin sources [11-13]. In recent studies, it has been determined that there are insect shells within bat guano and accordingly there is chitin in the bat guano $[14,15]$. In the current study, the ability to use bat guano as an alternative chitin source was investigated for the first time by means of determining the chitin characteristics within the excreta belonging to bat species that feed on insects.

According to data from the General Directorate of Mineral Research and Exploration in Turkey, there are approximately 40000 caves in Turkey, but only 1250 of those have been discovered and explored [16]. The aforementioned number of caves is only for Turkey. The number of caves across the world will be much greater. 
As is well known, caves are living spaces for bats and the excreta of these bats has been accumulating for many years and has therefore reached a high level. For instance, in the study conducted by Sikazwe and Waele [17] in Chipongwe and Kapongo caves in Zambia, 1218 and 2822 tons, respectively, of bat guano stocks were estimated. If bat guano is a viable source of chitin, the fact that there is a plentiful supply is a significant advantage.

Bats generally feed on terrestrial arthropods, and the external body parts of all these animals are formed from chitin. The guano within caves of insectivore bats can be utilized as a chitin source. Since bat guano is composed of a good many organic substances it is quite rich in carbon and nitrogen, and can be used in agriculture [18].

The bat guano used during this study belongs to Rhinolophus hipposideros (Bechstein, 1800). R. hipposideros, also known as the Horseshoe bat, is a bat species that is common throughout Turkey and feeds on insects. Its range is within Southeastern Asia, South and Central Europe and East Africa [19]. It feeds especially on mosquitoes, dragonflies (Odanata) and spiders [20].
The aim of this study is to examine the nature of bat guano and determine if it is a practical source of chitin, which has not been done previously. Chitosan is the product obtained from chitin. The chitin contents of bat's dry guano and the chitin's chitosan productivity will be determined. Moreover, the isolated chitin and synthesized chitosan will be characterized by means of FTIR, TGA, XRD, ESEM and elemental analyses, and their purity will be investigated.

\section{Materials and methods \\ Sample collection}

Bat guano samples were obtained from Karacamal Cave (Balçıhisar Town, Şuhut, Afyon, Turkey) in the inner western Anatolia region of Turkey on 11.11.2013. The GPS coordinates of the cave are $38^{\circ} 23^{\prime} \mathrm{N}, 30^{\circ} 28^{\prime} \mathrm{E}$, and the altitude is $1465 \mathrm{~m}$. It was determined that the bat species within this cave is $R$. hipposideros (Lesser horseshoe bat). Pictures of cave, bat guano and bat species were shown in Figure 1.

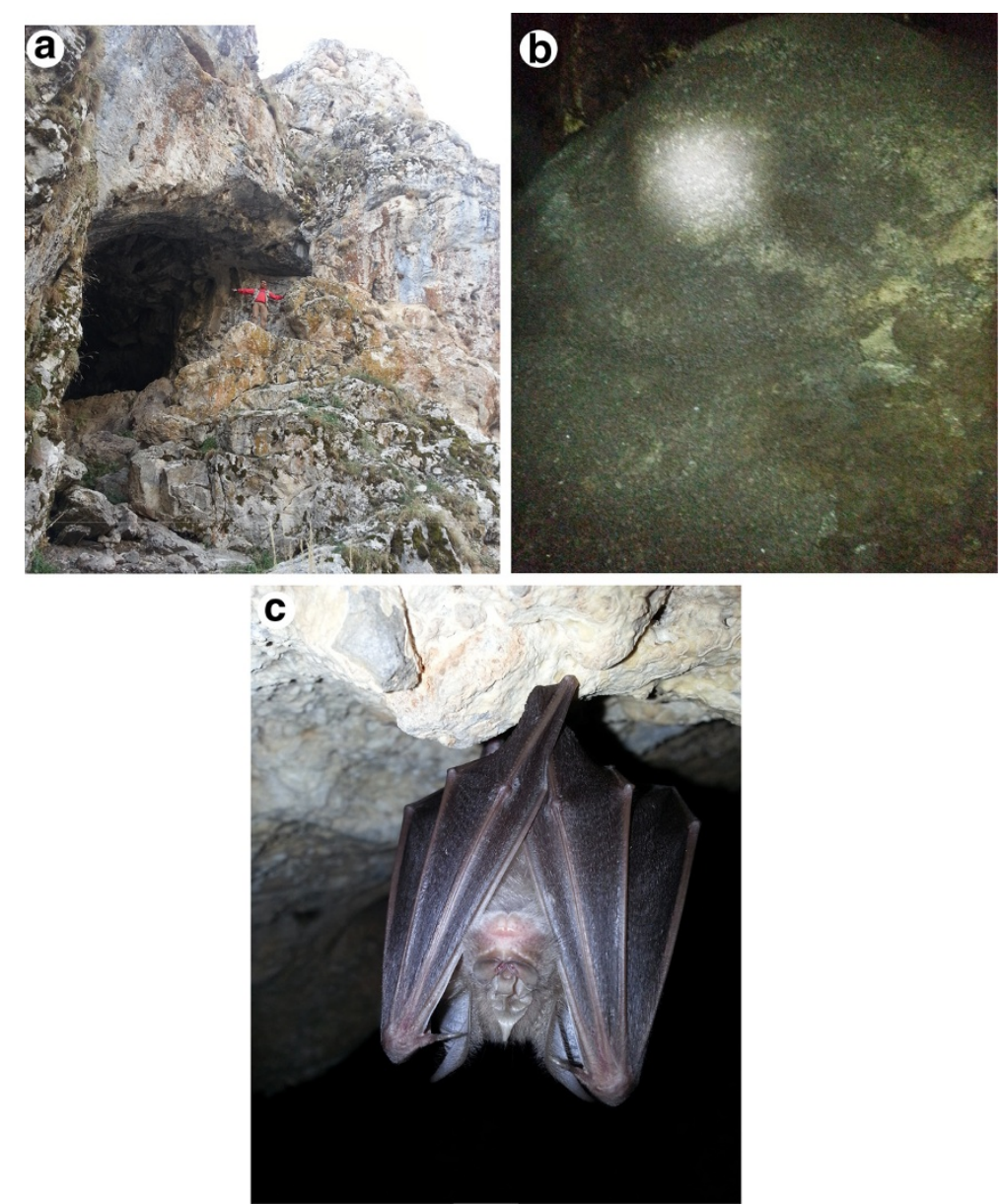

Figure 1 Karacamal cave. (a: entrance, b: bat guano in the cave and $\mathbf{c}$ : Rhinolophus hipposideros living in the cave). 


\section{Chitin extraction}

Bat guano samples were dried at $60^{\circ} \mathrm{C}$ in a drying oven for a week in the laboratory. Afterwards, $10 \mathrm{~g}$ of the dried sample were weighed on precision scales and refluxed in $4 \mathrm{M} \mathrm{HCl}$ solution for 24 hours at $50^{\circ} \mathrm{C}$. Afterwards, it was filtered through $1 \mu \mathrm{m}$ filter paper and distilled water was added until the $\mathrm{pH}$ became neutral. Then, the sample was refluxed in $4 \mathrm{M} \mathrm{NaOH}$ solution for 24 hours at $140^{\circ} \mathrm{C}$. Next, the refluxed sample was washed with distilled water and filtered via $1 \mu \mathrm{m}$ filter paper (S \& H Labware) until the $\mathrm{pH}$ became neutral. Later, samples were once again washed with distilled water and passed through a $1 \mu \mathrm{m}$ filter paper before blending them with chloroform, methanol and pure water for elemination of pigments, lipids and decolourisation in the ratio of 1:2:4 for 4 hours until the $\mathrm{pH}$ became neutral. Finally, the rest of the sample was dried within a drying oven at $60^{\circ} \mathrm{C}$ for 48 hours, and then weighed to determine the chitin contents of the bat guano.

Chitin extraction procedure was done four times to determine \% chitin content.

\section{Chitosan production}

From the dried chitin, $1 \mathrm{~g}$ was refluxed within $60 \%$ $\mathrm{NaOH}$ solution for 4 hours at $150^{\circ} \mathrm{C}$. Later, it was washed with distilled water and filtered through $1 \mu \mathrm{m}$ filter paper until the $\mathrm{pH}$ became neutral, and then it was dried at $60^{\circ} \mathrm{C}$ for 48 hours. The dry sample was weighted and the amount of chitosan produced from the bat guano was determined.

\section{Fourier transform infrared spectroscopy (FTIR)}

Fourier transform infrared (FTIR) spectroscopy was used to identify the chitin formation from the bat guano and the chitosan synthesized from the chitin. Moreover, from an examination of the FTIR bands the form of the chitin can be determined ( $\alpha, \beta$ and $\gamma$ ). In this study, $5 \mathrm{mg}$ samples of the chitin and chitosan from the bat guano were analyzed with a Perkin-Elmer FTIR spectrometer at $4000-625 \mathrm{~cm}^{-1}$.

\section{Thermogravimetric analysis (TGA)}

During thermogravimetric analysis (TGA) $3 \mathrm{mg}$ samples of the chitin and chitosan obtained from the bat guano were weighed and a warm-up operation was conducted from $25^{\circ} \mathrm{C}$ to $650^{\circ} \mathrm{C}$ by increasing the temperature by $10^{\circ} \mathrm{C}$ every minute. During this operation, the decomposition temperatures of the chitin and chitosan were noted and the thermal stability was deduced. With this analysis, the temperatures at which maximum decomposition of the chitin and chitosan occurred were identified, while the water content, total decomposed mass and ash content were also determined. For these analyses, an EXSTAR S11 7300 machine was used.

\section{X-ray crystallography (XRD)}

The X-ray crystallography (XRD) analysis determined whether chitin and chitosan were acquired or not, and the calculation of the crystalline index (CrI) values was carried out. The XRD analysis was conducted utilizing a Rigaku D max 2000 machine at $40 \mathrm{kV}, 30 \mathrm{~mA}$ and with a $2 \theta$ scan angle from $5^{\circ}$ to $45^{\circ}$. The CrI value was calculated according to the following formula:

$$
\mathrm{CrI}_{110}=\left[\left(\mathrm{I}_{110}-\mathrm{I}_{\mathrm{am}}\right) / \mathrm{I}_{110}\right] \times 100
$$

$\mathrm{I}_{110}=$ the highest intensity at $2 \theta 20^{\circ}$.

$I_{\mathrm{am}}=$ the amorphous diffraction intensity at $2 \theta 13^{\circ}$.

\section{Elemental analysis (EA)}

A Thermo Flash 2000 machine was utilized to determine the $\mathrm{C}, \mathrm{N}$ and $\mathrm{H}$ contents of the chitin and chitosan obtained from bat guano. The degree of acetylation (DA) of the chitin and degree of deacetylation (DD) of the chitosan were calculated using the formula below:

$$
\mathrm{DA} \text { or } \mathrm{DD}=[(\mathrm{C} / \mathrm{N}-5.14) / 1.72] \times 100
$$

\section{Environmental scanning electron microscopy (ESEM)}

A Quanta 200 FEG Environmental Scanning Electron Microscope (ESEM) was used to determine the surface morphology of the chitin and chitosan obtained from bat guano. To enable clear pictures of the samples to be taken during the ESEM analysis a gold coating process was carried out with a Gatan Precision Etching Coating System before filming.

\section{Results and discussion}

\section{Chitin content and chitosan yield of bat guano}

The chitin content in the bat's ( $R$. hipposideros) dry guano was observed to be $28 \%$ by weight. The chitosan productivity of this chitin was determined to be $79 \%$. The chitosan yield of dry bat guano was found to be about $22 \%$. In recent studies, $15-25 \%$ chitin has been isolated from the dried exoskeleton of Crustacea such as prawn, shrimp, crab and lobster [21-23]. It is noted that the chitin contents of the total body structure dry weight of insects including Agabus bipustulatus, Anax imperator, Bombyx mori, Holotrichia parallela, Hydrophilus piceus, Notonecta glauca, Ranatra linearis and silkworm chrysalides ranges from $10 \%$ to $20 \%$ among the different species [13,24-26]. Alternatively, it was presented by Sajomsang and Gonil [27] that $36 \%$ of cicada sloughs were chitin. In this study it was found that the chitin content of bat guano was higher than the insect species investigated previously and the shell structures of Crustacea including prawn, shrimp, crab and lobster. However, bat guano had a slightly lower chitin content than cicada sloughs. Similarly, it was found that krill and Artemia cyst structures 
have high chitin contents, like the bat guano $[28,29]$. Nevertheless, bat guano will be a more prominent source compared with krill and Artemia cyst structures thanks to the natural stocks and easy collection.

In this study, the greater proportion of chitin within bat guano in comparison to the shell structures of Crustacea such as crab, prawn and shrimp will provide an economic advantage. Moreover, upon the collection of the organic and inorganic substances from bat guano with $\mathrm{HCl}$ and $\mathrm{NaOH}$, uses for the remaining guano can be researched. Another opinion is to begin chitin isolation following the isolation and use of other organic and inorganic substances within the excreta in the order of their importance. Removing these substances will provide an advantage economically by increasing the chitin content of the bat guano's dry weight.
Mammals are represented by 5146 species, and approximately $20 \%$ of these species are bat species. Among the mammalians, bats have 1116 species followed by the rodentia consisting of 2277 species [30]. Turkey has the greatest variety of bats within the European and Mediterranean regions, which has been determined as 37 species [31]. All except for one species feed on insects, and some bat species are specialized to feed on certain insect groups [32]. Since the guano of insectivorous bats is diversified according to the insect species, the chitin rates obtained from guano belonging to various bat species and the physicochemical features of the obtained chitin will be diverse. Furthermore, the insect variety that the bat consumes as food within its ecosystem will also influence the physicochemical features of the chitin. In this study the isolated chitin was collected

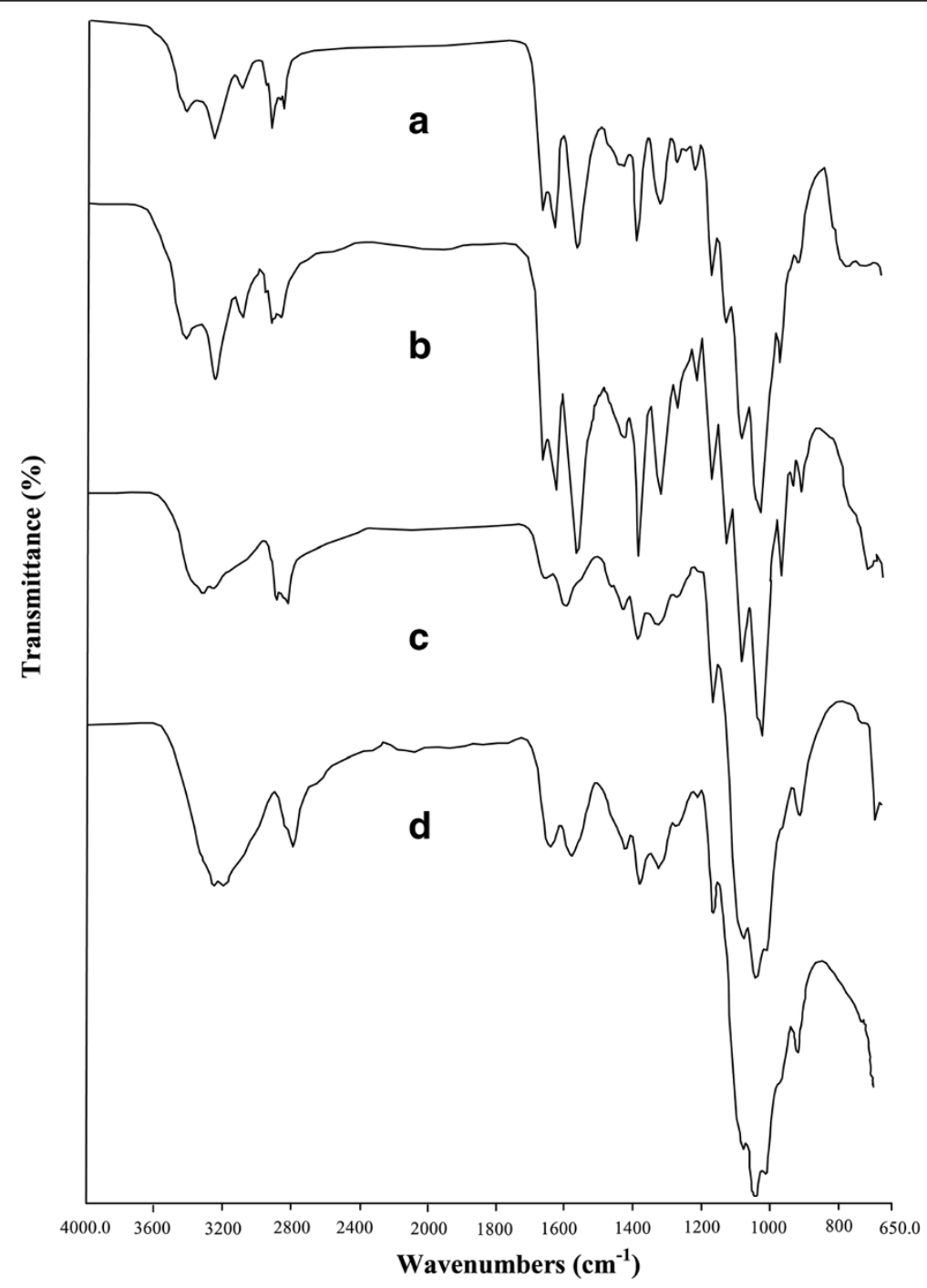

Figure 2 FTIR spectra of chitin and chitosan (a. chitin from bat guano, b. commercial chitin, c. chitosan from bat guano and d. commercial chitosan). 
Table 1 FTIR bands of chitin samples isolated from bat guano and commercial chitin

\begin{tabular}{|c|c|c|c|}
\hline \multirow{2}{*}{ Functional group and vibration modes } & \multirow{2}{*}{ Classification } & \multicolumn{2}{|c|}{ Wavenumber $\left(\mathrm{cm}^{-1}\right)$ frequency } \\
\hline & & Bat guano & Commercial chitin \\
\hline $\mathrm{O}-\mathrm{H}$ stretching & - & 3437 & 3437 \\
\hline $\mathrm{N}-\mathrm{H}$ stretching & - & 3263,3105 & $3261-3103$ \\
\hline $\mathrm{CH}_{3}$ sym. stretch and $\mathrm{CH}_{2}$ asym. stretch & Aliphatic compounds & 2921 & 2932 \\
\hline $\mathrm{CH}_{3}$ sym. stretch & Aliphatic compound & 2853 & 2862 \\
\hline $\mathrm{C}=\mathrm{O}$ secondary amide stretch & Amide I & 1656 & 1655 \\
\hline $\mathrm{C}=\mathrm{O}$ secondary amide stretch & Amide I & 1622 & 1621 \\
\hline $\mathrm{N}-\mathrm{H}$ bend, $\mathrm{C}-\mathrm{N}$ stretch & Amide II & 1554 & 1553 \\
\hline $\mathrm{CH}_{2}$ ending and $\mathrm{CH}_{3}$ deformation & - & 1411 & 1428 \\
\hline $\mathrm{CH}$ bend, $\mathrm{CH}_{3}$ sym. deformation & - & 1376 & 1375 \\
\hline $\mathrm{CH}_{2}$ wagging & Amida III, components of protein & 1308 & 1311 \\
\hline Asymmetric bridge oxygen stretching & - & 1154 & 1154 \\
\hline Asymmetric in-phase ring stretching mode & - & 1115 & 1115 \\
\hline $\mathrm{C}-\mathrm{O}-\mathrm{C}$ asym. stretch in phase ring & Saccharide rings & 1068 & 1069 \\
\hline $\mathrm{C}-\mathrm{O}$ asym. stretch in phase ring & - & 1012 & 1020 \\
\hline $\mathrm{CH}_{3}$ wagging & Along chain & 952 & 951 \\
\hline $\mathrm{CH}$ ring stretching & Saccharide rings & 899 & 897 \\
\hline
\end{tabular}

from guano belonging to just one bat species. In following studies the chitin contents in the guano of the same or disparate bat species from different environments will be presented along with discrepancies that can be used as a means of characterization of these chitins. Within this study, the utilization of bat guano as a chitin source was conducted for the first time and significant results were observed.

High concentration of $\mathrm{HCl}$ and $\mathrm{NaOH}$ and long reflux period were required to obtain high quality chitin. Lower concentrations and shorter time were tested but some minerals and protein residues could not be removed efficiently. And also, we found that these are optimum conditions for chitin isolation from the bat guano.

\section{FTIR}

The chitin FTIR spectrum obtained from bat guano is presented in Figure 2. One of the most significant techniques used in the differentiation of the $\alpha$ and $\beta$ forms is the FTIR spectrum. When observing chitin's FTIR

Table 2 FTIR bands of chitosan samples obtained from bat guano and commercial chitosan

\begin{tabular}{|c|c|c|}
\hline \multicolumn{2}{|c|}{ Wave number $\left(\mathrm{cm}^{-1}\right)$ frequency } & \multirow{2}{*}{ Vibration modes } \\
\hline Chitosan from bat guano & Commercial chitosan & \\
\hline 3364 & 3361 & $v\left(\mathrm{NH}_{2}\right)$ assoc. in primary amines and $v(\mathrm{OH})$ assoc. in pyranose ring \\
\hline 2920 & 2922 & $\mathrm{~V}_{\mathrm{as}}\left(\mathrm{CH}_{2}\right)$ in $\mathrm{CH}_{2} \mathrm{OH}$ group \\
\hline 2852 & 2867 & $v(\mathrm{C}-\mathrm{H})$ in pyranose ring \\
\hline 1656 & 1654 & $v(\mathrm{C}=\mathrm{O})$ in $\mathrm{NHCOCH}_{3}$ group (Amide I band) \\
\hline 1590 & 1589 & $v\left(\mathrm{NH}_{2}\right)$ in $\mathrm{NHCOCH}_{3}$ group (Amide II band) \\
\hline 1421 & 1420 & $\delta\left(\mathrm{CH}_{2}\right)$ in $\mathrm{CH}_{2} \mathrm{OH}$ group \\
\hline 1374 & 1375 & $\delta_{5}\left(\mathrm{CH}_{3}\right)$ in $\mathrm{NHCOCH}_{3}$ group \\
\hline 1315 & 1317 & $\delta(\mathrm{C}-\mathrm{H})$ in pyranose ring \\
\hline 1259 & 1259 & Complex vibrations of NHCO group (Amide III band) \\
\hline 1150 & 1149 & $v_{s}(C-O-C)$ (glycosidic linkage) \\
\hline 1060 & 1060 & $v_{a s}(C-O-C)$ (glycosidic linkage) \\
\hline 1024 & 1024 & $\vee(\mathrm{C}-\mathrm{O})$ in secondary $\mathrm{OH}$ group \\
\hline 987 & 986 & $v(\mathrm{C}-\mathrm{O})$ in primary $\mathrm{OH}$ group \\
\hline 891 & 892 & Pyranose ring skeletal vibrations \\
\hline
\end{tabular}


spectrum with the $\alpha$ form, the Amide I band gives two bands at 1660 and $1620 \mathrm{~cm}^{-1}[33,34]$. For chitin in the $\beta$ form, just one band is given at $1620 \mathrm{~cm}^{-1}$ due to the intermolecular hydrogen bonds [35]. In this study the availability of two bands at 1656 and $1622 \mathrm{~cm}^{-1}$ for the chitin obtained from the bat guano is an indicator of the fact that the chitin is in the $\alpha$ form. More detailed information is included in Table 1.

The FTIR spectrum of the chitosan obtained from the bat guano is shown in Figure 2, and there are two characteristic bands present. These are as follows: $v(\mathrm{C}=\mathrm{O})$ in the $\mathrm{NHCOCH}_{3}$ group (Amide I band) band at $1650 \mathrm{~cm}^{-1}$ and $v\left(\mathrm{NH}_{2}\right)$ in the $\mathrm{NHCOCH}_{3}$ group (Amide II band) band at $1590 \mathrm{~cm}^{-1}$ [36,37]. For the chitosan obtained from bat guano, the availability of two bands at $1656 \mathrm{~cm}^{-1}$ and $1590 \mathrm{~cm}^{-1}$ demonstrates its formation. Other significant bands are presented in Table 2.

In addition, the FTIR spectrum results for the chitin and chitosan from bat guano and the FTIR spectrum results for commercial chitin and chitosan purchased from Sigma Aldrich were compared and it was observed that the results showed considerable similarity.

\section{TGA}

For the chitin and chitosan obtained from the bat guano, the mass loss was observed in two stages (Figure 3). In the first stage, mass loss rates of $4 \%$ and $8 \%$ for chitin and chitosan were observed respectively, and this loss was due to water evaporation within the structure. In the second stage, mass loss rates of $79 \%$ and $62 \%$ for the chitin and chitosan were observed respectively (Figure 3).
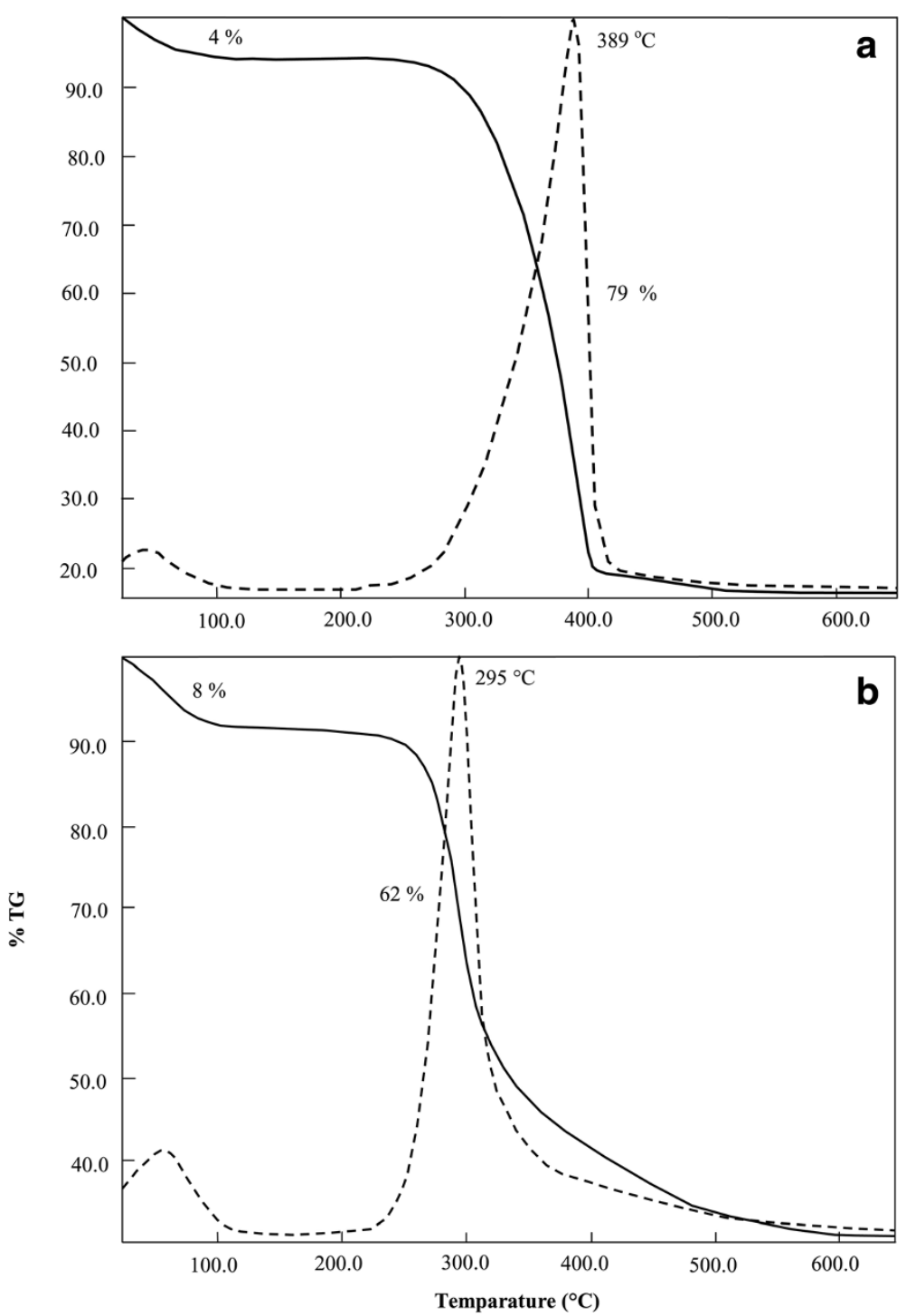

Figure 3 Thermogravimetric analysis of chitin and chitosan obtained from bat guano (a. chitin and b. chitosan). 
The mass loss observed at this stage was due to the decomposition of the chitin and chitosan molecules. It was observed that the total ash content was $17 \%$ for chitin and 30\% for chitosan. The temperature (DTGmax) at which the greatest decomposition was observed was $389^{\circ} \mathrm{C}$ for chitin and $295^{\circ} \mathrm{C}$ for chitosan.

When the results of TGA analyses of chitin and chitosan are considered from previous studies, the mass loss was observed at two stages, which is the same as in the current study $[25,26,29,34]$. Nevertheless, when we consider the results in the former studies, it was found that the thermal stability of chitin is higher than chitosan [25]. In this study, it was also observed that the thermal stability of the chitin isolated from the bat guano is higher than that of chitosan. The DTGmax values of the alpha chitin isolated from other organisms such as crab, shrimp or insects are around $380^{\circ} \mathrm{C}$, and for chitosan it is $300^{\circ} \mathrm{C}$ [25-27]. The DTGmax values observed for chitin and chitosan in this study also show similarity with former studies. These results show us that the chitin and chitosan isolated from bat guano are in accordance with the results observed in previous studies.

\section{XRD}

The XRD analysis of chitin isolated from bat guano revealed peaks at 9.32, 12.84, 19.42, 21.06, 23.38 and $26.64^{\circ}$. The strongest peak was at $19.42^{\circ}$ and this was followed by the one at $9.32^{\circ}$ (Figure 4). The XRD peaks of the chitin isolated from the bat guano show considerable similarity with the alpha chitins isolated from organisms such as insects, fungi, crab, shrimp, krill, Gammarus and crustacean
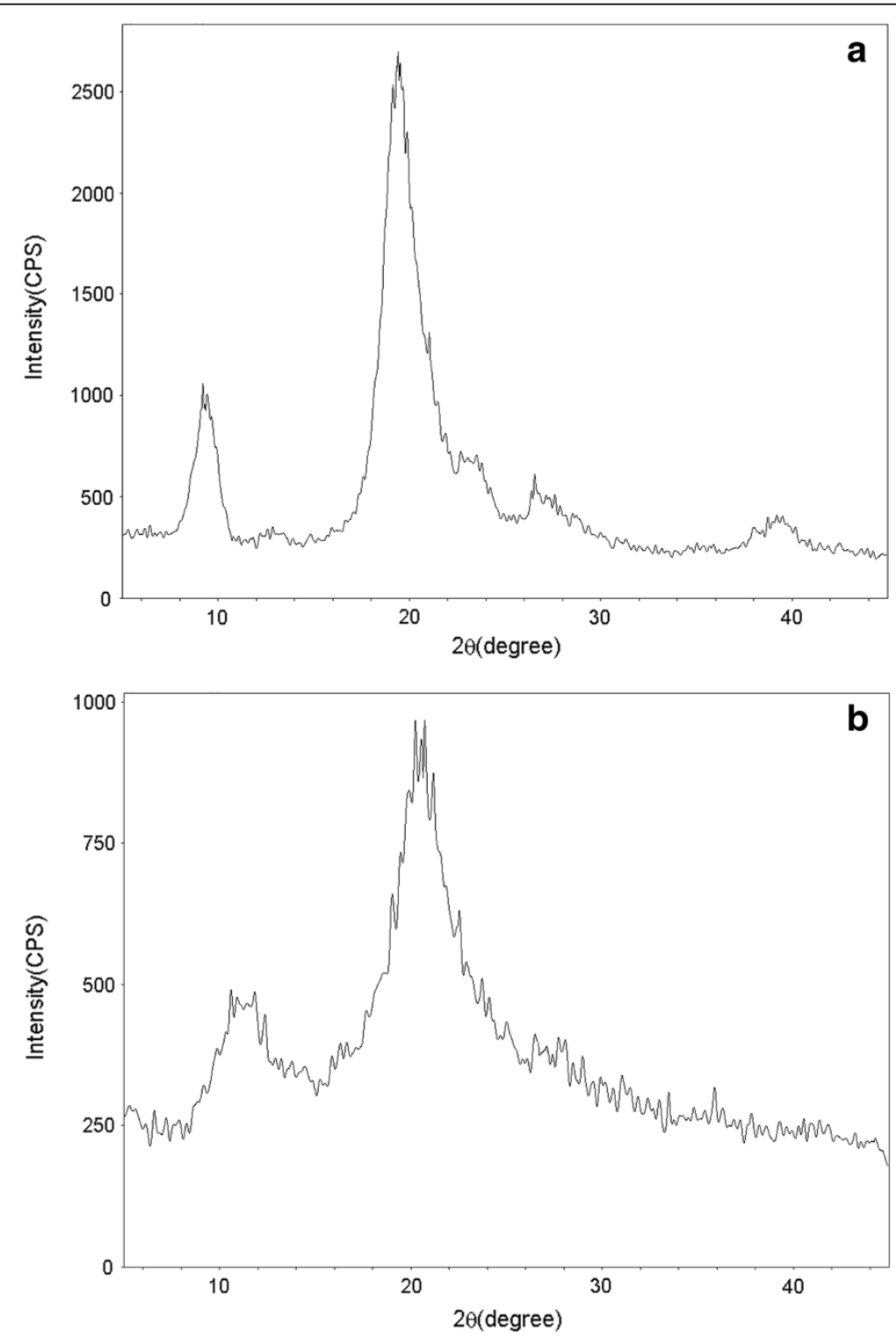

Figure 4 XRD patterns of chitin and chitosan obtained from bat guano (a. chitin and b. chitosan). 
resting eggs in previous studies [11,13,21,24,38-40]. The characteristic bands for alpha chitin are two sharp peaks of approximately 9 and $19^{\circ}$ and then four weak peaks of $13,21,23$ and $26^{\circ}$ on average. The two sharp peaks observed for chitosan synthesized from bat guano chitin were at 10.58 and $20.72^{\circ}$. Two peaks located at 10 and $20^{\circ}$ on average have been observed from chitosans isolated from organisms such as shrimp, crab and insects, which is similar to the chitosan obtained from the bat guano in this study [41,42].

The CrI value of the bat guano chitin was calculated as $85.49 \%$. While the CrI values of chitins isolated from organisms such as crab and insects in former studies were observed to be between 54 and $91 \%[13,26]$. Moreover, it was observed that chitins isolated from fungi and resting eggs have quite low $\mathrm{CrI}$ values [11]. The CrI value of chitin isolated from bat guano in this study shows similarity to the chitins isolated from insects and crabs in former studies. In this result, it was observed that the bat guano in this study belongs to $R$. hipposideros and this species feeds on insects. In addition, it was observed that the external skeleton of the insects could not be digested and was therefore excreted.

The CrI value of the chitosan from the bat guano was calculated as $58.51 \%$. This value is quite low when compared with the $\mathrm{Crl}$ value of the chitin. This is due to the stability of the chitin being decreased as a result of deacetylation, and accordingly its crystallinity value is scaled down. The lower $\mathrm{Crl}$ value of the chitosan in comparison to the chitin is an indicator that the chitosan is formed form the bat guano chitin. In the study conducted by Abdou et al. [21] it was noted that the Crl values of the chitosans obtained from cuttlefish, squid pens, shrimp and crab shells ranged between 36 and $71 \%$. The Crl value of the chitosan from the bat guano is moderate in comparison to the values obtained from other living creatures.

\section{Elemental analysis}

It was observed that the chitin isolated from the bat guano contained $C, N$ and $H$ at the rates of 47.52, 6.47
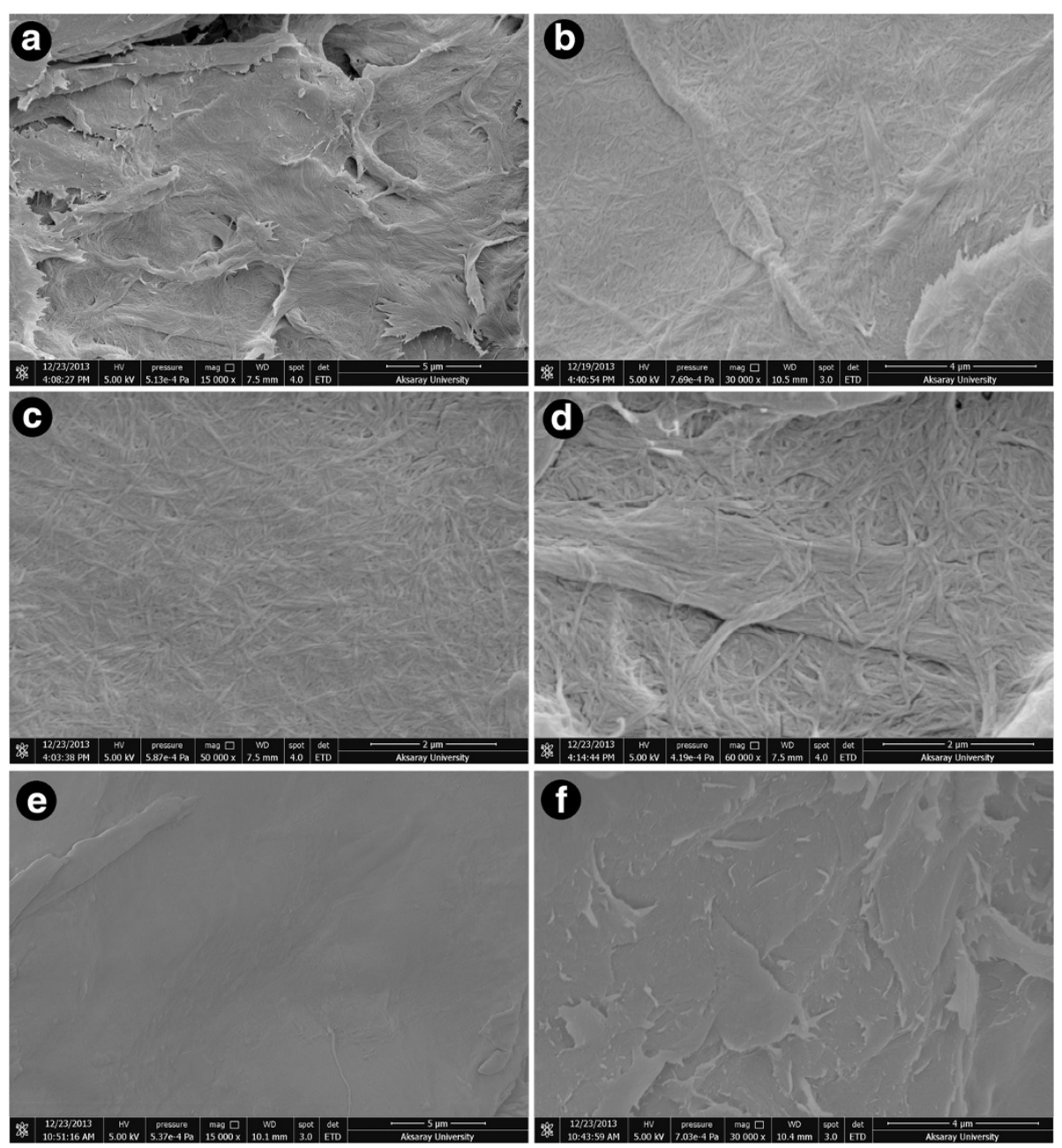

Figure 5 SEM pictures of chitin and chitosan produced from bat guano (a, b, c, d. chitin and e, f. chitosan). 
and $6.53 \%$ respectively. The $N$ value of completely acetylated chitin was determined to be $6.89 \%$ [38], and the value in this study was close to this rate. The $N$ content of chitin in other studies was observed between 2.96 and $6.8 \%[11,13,26,38]$. As this value is close to $6.89 \%$, it demonstrates the chitin's purity. The DA value of the chitin was calculated and set as $128 \%$. The DA value of completely acetylated chitin is $100 \%$ [27]. In this study the value observed is greater than $100 \%$, which demonstrates that remnants of inorganic materials have not been completely removed from the chitin. It has been observed that the DA values of chitins isolated from various organisms in previous studies were much greater than $100 \%$. As in these previous studies, it demonstrates that there are remnants of inorganic materials within the chitin structure.

The $C, N$ and $H$ values of chitosan from the bat guano account for $45.2,7.30$ and $7.02 \%$ respectively. The higher $N$ value for the chitosan in comparison to the $N$ value of the chitin demonstrates that the chitin is deacetylated and there is chitosan formation. According to the elemental analysis results, the DD value of the chitosan was calculated as $61 \%$. A DD value that is close to $100 \%$ demonstrates that the purity of the chitosan is high. It can be stated that the DD value of the chitosan obtained in this study is at a medium to low rate. In follow up studies, the incubation period in the $\mathrm{NaOH}$ solution could be prolonged during the process of chitosan synthesis from chitin, so chitosan with a higher DD value can be obtained.

\section{ESEM}

When the ESEM images of the surface morphologies of the chitin and chitosan extracted from the bat guano were observed, they could easily be differentiated from one another. It was observed that the surface of the chitin consisted of nanofibres (Figure 5). These nanofibers were nested and demonstrated a complex distribution in which they were attached to one another. The surface of the chitosan was smoother and the nanofibers were thin with a fractured appearance. The chitins upon both the chitin and chitosan were attached to one another, and therefore the width of the nanofibers could not be measured.

In previous studies, it was observed that the surface of the chitin was formed from three different types in general. The first of these types has the outside surface formed form nanofibers and nanopores [22,40,43]. The second has the surface with only nanofibers, without nanopores $[11,26,44]$. The third one has the surface with both nanofibers and nanopores together [29,39]. In this study, the chitin and chitosan obtained from the bat guano have surface morphologies that are formed from only nanofibers, and are accordingly the second type. In the study conducted by Kaya et al. [26], all the chitins and chitosans obtained from five insect species were formed from only nanofibers. In this study, it is as expected that the surfaces of the chitin and chitosan are formed from only nanofibers as the chitin in the bat guano comes from insect shells.

\section{Conclusion}

Chitin and chitosan are biomaterials that can be produced from bat guano and are more economically valuable than the guano that they come from. Bat guano consists of high levels of chitin and chitosan. To utilize this chitin and chitosan effectively, they were characterized with FTIR, TGA, XRD, SEM and elemental analysis methods. Another significant feature of this study was the fact that it was determined that the bats could not digest the chitin and they removed it via excretion. When we take into account the fact that there are probably 100 million tons of bat guano available across the world, it could be a significant source of chitin and its derivatives.

\section{Competing interests}

The authors declare that they have no competing interests.

\section{Authors' contributions}

The original idea and design of the experiments belonged to MK, OS and TT. The bat guano sample was collected by OS and TT. The chitin isolation was done by MK. All the analyses (except FTIR) were done by MK. FTIR analysis was performed by TB. All authors read and approved the final manuscript.

\section{Acknowledgement}

We would like to thank Prof. Dr. Ahmet KARATAS for bat species identification. This study was funded by Aksaray University BAP (2014-005).

\section{Author details}

'Department of Biotechnology and Molecular Biology, Faculty of Science and Letters Aksaray University, Aksaray 68100, Turkey. ${ }^{2}$ Science and Technology Application and Research Center, Aksaray University, Aksaray 68100, Turkey. ${ }^{3}$ Department of Biology, Science and Arts Faculty, Niğde University, Niğde, TR 51200, Turkey. ${ }^{4}$ Department of Chemistry, Faculty of Science and Letters, Aksaray University, Aksaray, Turkey.

Received: 23 May 2014 Accepted: 6 August 2014 Published: 14 August 2014

\section{References}

1. Brunner E, Richthammer P, Ehrlich H, Paasch S, Simon P, Ueberlein S, Van Pee KH: Chitin-based organic networks - an integral part of cell wall biosilica from the diatom Thalassiosira pseudonana. Angew Chem Int Ed 2009, 48:9724-9727.

2. Rinaudo M: Chitin and chitosan: properties and applications. Prog Polym Sci 2006, 3:603-632.

3. Bo M, Bavestrello G, Kurek D, Paasch S, Brunner E, Born R, Galli R, Stelling AL, Sivkov VN, Petrova OV, Vyalikh D, Kummer K, Molodtsov SL, Nowak D, Nowak J, Ehrlich $\mathrm{H}$ : Isolation and identification of chitin in black coral Paranthipates larix (Anthozoa: Cnidaria). Int J Biol Macromol 2012, 51:129-137.

4. Aranaz I, Mengibar M, Harris R, Panos I, Miralles B, Acosta N, Galed G, Heras A: Functional characterization of chitin and chitosan. Curr Chem Biol 2009, 3:203-230.

5. Zhao Y, Park RD, Muzzarelli RA: Chitin deacetylases: properties and applications. Mar Drugs 2010, 8:24-46.

6. Synowiecki J, Al-Khateeb NA: Production, properties, and some new applications of chitin and its derivatives. Crit Rev Food Sci Nutr 2003, 43:145-171. 
7. Dutta PK, Dutta J, Tripathi VS: Chitin and chitosan: chemistry, properties and applications. J Sci Ind Res 2004, 63:20-31.

8. Ehrlich $\mathrm{H}$ : Chitin and collagen as universal and alternative templates in biomineralization. Int Geol Rev 2010, 52:661-699.

9. Park BK, Kim MM: Applications of chitin and its derivatives in biological medicine. Int J Mol Sci 2010, 11:5152-5164.

10. Ehrlich $H$, Simon $P$, Motylenko M, Wysokowski M, Bazhenov W, Galli R, Stelling AL, Stawski D, Ilan M, Stöcker H, Abendroth B, Born R, Jesionowski T, Kurzydlowski KJ, Meyer DC: Extreme biomimetics: formation of zirconium dioxide nanophase using chitinous scaffolds under hydrothermal conditions. J Mater Chem 2013, 1:5092-5099.

11. Wysokowski M, Motylenko M, Bazhenov W, Stawski D, Petrenko I, Ehrlich A, Behm T, Kljajic Z, Stelling AL, Jesionowski T, Ehrlich H: Poriferan chitin as a template for hydrothermal zirconia deposition. Front Mater Sci 2013, 7(3):248-260.

12. Ifuku S, Nomura R, Morimoto M, Saimoto H: Preparation of chitin nano fibers from mushrooms. Materials 2011, 4:1417-1425.

13. Liu S, Sun J, Yu L, Zhang C, Bi J, Zhu F, Qu M, Jiang C, Yang Q: Extraction and characterization of chitin from the beetle Holotrichia parallela motschulsky. Molecules 2012, 17:4604-4611.

14. Ferreira RL, Prous $X$, Martins RP: Structure of bat guano communities in a dry Brazilian cave. Trop Zool 2007, 20:55-74.

15. Wurster CM, McFarlane DA, Bird MI, Ascough P, Athfield NB: Stable isotopes of subfossil bat guano as a long-term environmental archive: insights from a grand canyon cave deposit. J Cave Karst Stud 2010, 72:111-121.

16. Topçu A, Seyyar O, Demircan N: A contribution to the cave spider fauna of Turkey (Araneae). Zool Middle East 2013, 59:91-92.

17. Sikazwe ON, De Waele B: Assessment of the quality and reserves of bat guano at chipongwe and kapongo caves near lusaka as fertiliser material. Unza J Sci Technol 2004, 1(3):32-42.

18. Bird MI, Boobyer EM, Bryant C, Lewis HA, Paz V, Stephens WE: A long record of environmental change from bat guano deposits in Makangit Cave, Palawan, Philippines. T Roy Soc Edın-Earth 2007, 98:59-69.

19. Jacobs D, Cotterill FPD, Taylor PJ, Aulagnier S, Juste J, Spitzenberger F, Hutson AM: Rhinolophus hipposideros. In IUCN 2013. IUCN Red List of Threatened Species. 2008. Version 2013.2. <www.iucnredlist.org> Downloaded on 13 February 2014.

20. Csorba G, Ujhelyi P, Thomas N: Horseshoe bats of the world (Chiroptera: Rhinolophidae). Shropshire, United Kingdom: Alana Books; 2003.

21. Abdou ES, Nagy KSA, Elsabee MZ: Extraction and characterization of chitin and chitosan from local sources. Bioresource Technol 2008, 99:1359-1367.

22. Al Sagheer FA, Al Sughayer MA, Muslim S, Elsabee MZ: Extraction and characterization of chitin and chitosan from marine sources in Arabian Gulf Carbohydr. Polym 2009, 77:410-419.

23. Youn DK, No HK, Prinyawiwatkul W: Physicochemical and functional properties of chitosans prepared from shells of crabs harvested in three different years. Carbohydr Polym 2009, 78:41-45.

24. Zhang M, Haga A, Sekigushi H, Hirano S: Structure of insect chitin isolated from beetle larva cuticle and silkworm (Bombyx mori) pupa exuvia. Int J Biol Macromol 2000, 27:99-105.

25. Paulino AT, Siminato Jl, Carcia JC, Nozaki J: Characterization of chitosan and chitin produced from silkworm chrysalides. Carbohydr Polym 2006, 64:98-103.

26. Kaya M, Baran T, Mentes A, Sezen G, Asaroglu M, Tozak KO: Extraction and characterization of a-chitin and chitosan from six different aquatic invertebrates. Food Biophys 2014, 9:145-157.

27. Sajomsang W, Gonil P: Preparation and characterization of a-chitin from cicada sloughs. Mater Sci Eng 2010, 30:357-363.

28. Tajik H, Moradi M, Rohani SMR, Erfani AM, Jalali FSS: Preparation of chitosan from Brine shrimp (Artemia urmiana) cyst shells and effects of different chemical processing sequences on the physicochemical and functional properties of the product. Molecules 2008, 13:1263-1274.

29. Wang Y, Chang Y, Yu L, Zhang C, Xu X, Xue Y, Li Z, Xue C: Crystalline structure and thermal property characterization of chitin from Antarctic krill (Euphausia superba). Carbohydr Polym 2013, 92:90-97.

30. Wilson DE, Reeder DAM: Mammal Species of the World. A taxonomic and geographic reference. 3rd edition. Baltimore: Johns Hopkins University Press; 2005.

31. Karataş A, Sachanowicz K: Noteworthy bat records from Upper Mesopotamia, Turkey (Chiroptera). Lynx (Praha) 2008, 39:103-108.
32. Whitaker JO, Karatas A: Food and feeding habits of some bats from Turkey. Acta Chiropterol 2009, 11:393-403.

33. Focher B, Naggi A, Torri G, Cosani A, Terbojevich M: Chitosans from Euphausia superba. 2: characterization of solid state structure. Carbohydr Polym 1992, 18:43-49.

34. Jang MK, Kong BG, Jeong $\mathrm{Yl}$, Lee $\mathrm{CH}$, Nah JW: Physicochemical characterization of $\alpha$-chitin, $\beta$-chitin, and $\gamma$-chitin separated from natural resources. J Polym Sci Part A: Polym Chem 2004, 42:3423-3432.

35. Gardner $\mathrm{KH}$, Blackwell J: Refinement of the structure of $\beta$-chitin. Biopolymers 1975, 14:1581-1595.

36. Chatterjee S, Adhya M, Guha AK, Chatterjee BP: Chitosan from Mucor rouxii: production and physico-chemical characterization. Process Biochem 2005 40:395-400.

37. Peng T, Goosen MFA: Structural changes of $\mathrm{pH}$-sensitive chitosan/polyether hydrogels in different pH solution. J Polym Sci A1 1994, 32:591-596.

38. Cárdenas G, Carbrera G, Taboada E, Miranda SP: Chitin characterization by SEM FTIR, XRD, and ${ }^{13} \mathrm{C}$ cross polarization/mass angle spinning NMR. J Appl Polym Sci 2004, 93:1876-1885.

39. Kaya M, Tozak KO, Baran T, Sezen G, Sargin I: Natural porous and nano fiber Chitin structure from Gammarus argaeus (Gammaridae Crustacea). Excli J 2013, 12:503-510.

40. Kaya M, Sargin I, Tozak KO, Baran T, Erdogan S, Sezen G: Chitin extraction and characterization from Daphnia magna resting eggs. Int J Biol Macromol 2013, 61:459-464.

41. Yen MT, Yang JH, Mau JL: Physicochemical characterization of chitin and chitosan from crab shells. Carbohydr Polym 2009, 75:15-21.

42. Kucukgulmez A, Celik M, Yanar Y, Sen D, Polat H, Kadak AE: Physicochemical characterization of chitosan extracted from Metapenaeus stebbingi shells. Food Chem 2011, 126:1144-1148.

43. Yen MT, Mau JL: Selected physical properties of chitin prepared from shiitake stipes. Lwt - Food Sci Technol 2007, 40:558-563.

44. Chan HY, Chen MH, Yuan GF: Fungal chitosan. Fungal Sci 2001, 16:39-52.

doi:10.1186/s12983-014-0059-8

Cite this article as: Kaya et al:: Bat guano as new and attractive chitin and chitosan source. Frontiers in Zoology 2014 11:59.

\section{Submit your next manuscript to BioMed Central and take full advantage of:}

- Convenient online submission

- Thorough peer review

- No space constraints or color figure charges

- Immediate publication on acceptance

- Inclusion in PubMed, CAS, Scopus and Google Scholar

- Research which is freely available for redistribution
C Biomed Central 